\title{
Aerobacterial Vaginosis among Women Attending an Infertility Clinic at a Tertiary Care Hospital in Chennai, India and Susceptibility Pattern of Isolates
}

\author{
Abigail R. Sopia ${ }^{1,2}$ (D) Pushpa Innocent D. Joseph ${ }^{3}$ D, M. Kalyani² ${ }^{\mathbb{D}}$, B. Ananthi ${ }^{1}$, \\ Suresh Dhanaraj ${ }^{4}$ (D) and Allen John Henry** (D)
}

${ }^{1}$ A.C.S. Medical College and Hospitals, Chennai - 600077, Tamil Nadu, India.

${ }^{2}$ Saveetha Institute of Medical and Technical Sciences, Chennai - 600077, Tamil Nadu, India.

${ }^{3}$ Karpaga Vinayaga Medical Sciences and Research Center, Kanchipuram - 603308, Tamil Nadu India.

${ }^{4}$ Vels Institute of Science Technology and Advanced Studies, Chennai - 600117, Tamil Nadu, India.

\begin{abstract}
Genital infections and subsequent vaginosis diagnosed through high vaginal swab in women is caused due to fungi or bacteria. The presented study focused on determining the types, numbers and antibacterial susceptibility pattern of aerobic bacteria causing vaginosis in 147 female patients attending infertility centre in Chennai, Tamil Nadu, India. Candida spp. caused $17 \%$ of infections with $15.7 \%$ of vaginosis caused by E.coli, Klebsiella spp., Acinetobacter spp., Citrobacter spp. and Gram positive cocci - Methicillin Sensitive Staphylococcus aureus (MSSA), Coagulase Negative Staphylococci(CONS), Staphylococcus aureus and Enterococcus spp. causing $12.9 \%$ of vaginitis in the study population. A total of 20 different antibiotics - cell wall inhibitors, protein synthesis inhibitors and nucleic acid synthesis inhibitors; were tested to determine the response of bacterial isolates by Kirby-Bauer disc diffusion method. The study result determined that the most effective drug for treating Gram positive bacterial vaginitis as per CLSI guidelines based on susceptibility pattern as: Linezolid(100\%), Gentamycin(91.6\%), Amikacin(87.5\%),Erythromycin(79.2\%), Co-Trimoxazole(72.2\%), Ciprofloxacin(65.6\%) and least Chloramphenicol(44.3\%). High level gentamycin(83.3\%) was found to be effective in treating Enterococci. The descending order of susceptibility of Gram negative aerobacteria causing vaginitis as per CLSI guidelines are: Amikacin(87.5\%), Gentamycin(82.5\%), Cefoperazone sulbactam (76.3\%), Ciprofloxacin(68.5\%), Ceftazidime(62.5\%) and least Amoxyclav(25\%).All Gram negative bacteria tested were susceptible to-Imipenem and Meropenem as well as Chloramphenicol. Ceftriaxone (87.5\%) and Nitrofurantoin(72.3\%) among other antibiotics was effective against Gram negative bacteria while all Enterobacteriaceae members were found to be resistant to tetracycline.
\end{abstract}

Keywords: Vaginitis, Antibiotic Susceptibility pattern, Imipenem, Meropenem, Amikacin, CLSI guidelines, Nitrofurantoin

*Correspondence: velsmicrobiology@gmail.com

(Received: September 10, 2020; accepted: January 12, 2021)

Citation: Sopia AR, Joseph PID, Kalyani M, Ananthi B, Dhanaraj S, Henry AJ. Aerobacterial Vaginosis among Women Attending an Infertility Clinic at a Tertiary Care Hospital in Chennai, India and Susceptibility Pattern of Isolates. J Pure Appl Microbiol. 2021;15(1):194-200. doi:10.22207/JPAM.15.1.14

(C) The Author(s) 2021. Open Access. This article is distributed under the terms of the Creative Commons Attribution 4.0 International License which permits unrestricted use, sharing, distribution, and reproduction in any medium, provided you give appropriate credit to the original author(s) and the source, provide a link to the Creative Commons license, and indicate if changes were made. 


\section{INTRODUCTION}

Bacterial vaginosis(BV) occurs due to imbalance in biofilm bacteria of vagina especially inherent Lactobacillus spp. and the increased presence of opportunistic bacterial pathogen ${ }^{1}$. Predisposing factors for BV are generally associated with change in $\mathrm{pH}$, increased glycogen levels, hormonal status, age, and demographic factors. Clinical symptom of BV is vaginitis presented as vaginal inflammation with accompanying vaginal discharge with fishy odour, itching, vaginal irritation etc. Vaginitis is one of the most frequently presented clinical picture among women reporting to Gynaecology division in hospitals. Grey-white thin vaginal discharge with fishy odour may be due to microbial causes such as Aerobic Vaginitis(AV), BV, Trichomonal Vaginitis(TV) or Vulvovaginal Candidiasis(VVC) ${ }^{2}$.

Women in the reproductive age group of 19-45 years are most susceptible to bacterial vaginosis. Worldwide prevalence rate of $\mathrm{BV}$ ranges from $5 \%-70 \%^{3}$ and in India the rate of prevalence is $30 \%{ }^{4}$. Salpingitis occurs in $35 \%$ of women with $\mathrm{BV}$ and $2.5 \%$ of such patients become infertile ${ }^{5}$. Aerobic vaginitis and the treatment of infections in pregnant women is associated with higher incidence of premature rupture of membranes for the patient ${ }^{6}$. High prevalence (70\%) of vulvovaginal candidiasis caused by Candida spp. leads to routine treatment with anticandidal drugs and recurrent candidiasis is prevalent ${ }^{7}$. The lower one-third of the vagina is home to hundreds of bacteria both aerobic and anaerobic belonging to grampositive and gram-negative groups ${ }^{8}$. The collection of high vaginal swab and isolation of infective organism should be a mandated procedure as misdiagnosis is common in infertile women ${ }^{9}$. The existing method of treatment with antifungals for vaginosis is a cause for concern. The present study aims to identify and categorize the bacterial agents of vaginosis and analyse their antibacterial susceptibility pattern.

\section{MATERIALS AND METHODS}

The study was conducted for a period of one year from April 2018 to March 2019. Patients reporting to infertility clinic in ACS Medical College and Hospitals, Chennai, Tamil Nadu, India were included in the study. The study was approved by the institutional Ethics committee
(Approval number: 001/04/2017/IEC/SU dated: 27/04/2017). Women patients in the reproductive age group $19-45$ years were included in the study ${ }^{10}$. Patients having genital malignancy, antibiotic utilization by any route in the month prior to sample collection, having TV, Gardnerella vaginalis or Neisseria gonorrhoea and those above or below the reproductive age were excluded from the study ${ }^{11,12}$. A detailed questionnaire on age, medical history, infertility status and relevant parameters was requested and informed consent for inclusion in the study obtained. As per study design a total of 153 samples were collected and 6 were excluded as they did not match inclusion criteria.

High vaginal swab (HVS) in triplicate from each patient was collected as per standard protocol by trained nurses. In brief: Sterile speculum was inserted into vagina and from the vaginal walls samples were aseptically collected and placed in sterile saline, transported to microbiology laboratory for investigations ${ }^{13}$. First HVS swab was used for bacterial cytology by Gram staining and second HVS sample used for wet mount analysis. Third HVS sample was used for isolation of bacteria using MacConkey agar and Blood agar ${ }^{14}$. The culture plates were incubated at $37^{\circ} \mathrm{C}$ overnight for cultivation of aerobacteria ${ }^{15}$. The suspected growth of aerobacteria on culture plates were subjected to various biochemical tests as per standard guidelines in Quality assured microbiology laboratory at Department of Microbiology, ACS Medical College and Hospitals ${ }^{16,17}$.

Kirby Bauer disk diffusion method for antibiotic susceptibility testing was performed as per CLSI guidelines ${ }^{18}$. The Muller-Hinton agar (MHA) plates were swabbed with 0.5/ 1.0 McFarland standard broth culture of bacteria. Standard commercially available antibiotic discs (Hi-Media, India) were placed on the surface of MHA plate as per the pattern wherein $24 \mathrm{~mm}$ distance maintained between adjacent discs and $20 \mathrm{~mm}$ distance between edge of plate and disc. The plates were incubated at $35^{\circ} \mathrm{C} \pm 2^{\circ} \mathrm{C}$ overnight and results recorded ${ }^{19}$. Antibiotics included in susceptibility testing of bacterial isolates were as follows: Amikacin (AK; $30 \mathrm{mcg} / \mathrm{disc}$ ), Amoxyclav (AMC; $30 \mathrm{mcg} / \mathrm{disc}$ ), Ampicillin (AMP; $10 \mathrm{mcg} /$ disc), Cefoperazone sulbactam (CFS; $50 / 50 \mathrm{mcg} /$ disc), Cefotaxime (CTX; $30 \mathrm{mcg} / \mathrm{disc}$ ), Ceftazidime 
(CAZ; $30 \mathrm{mcg} / \mathrm{disc}$ ), Ceftriaxone (CTR; $30 \mathrm{mcg} / \mathrm{disc}$ ), Chloramphenicol (C; $30 \mathrm{mcg} /$ disc), Ciprofloxacin (CIP; $5 \mathrm{mcg} / \mathrm{disc}$ ), Co-Trimoxazole (COT; $25 \mathrm{mcg} /$ disc), Erythromycin (E; $15 \mathrm{mcg} /$ disc), Gentamycin (G; $10 \mathrm{mcg} / \mathrm{disc}$ ), High Level Gentamycin (HLG; $120 \mathrm{mcg} / \mathrm{disc}$ ), Imipenem (IPM; $10 \mathrm{mcg} / \mathrm{disc}$ ), Linezolid (LZ; $10 \mathrm{mcg} / \mathrm{disc}$ ), Meropenem (MRP; $10 \mathrm{mcg} / \mathrm{disc}$ ), Nitrofurantoin (NIT; $300 \mathrm{mcg} / \mathrm{disc}$ ), Norfloxacin (NX; $10 \mathrm{mcg} / \mathrm{disc}$ ), Penicillin (P; 10 $\mathrm{mcg} /$ disc), and Tetracycline ( $\mathrm{T} ; 10 \mathrm{mcg} / \mathrm{disc}$ ). Data analysis was done using IBM SPSS Statistics for Windows, version XX (IBM Corp., Armonk, N.Y., USA) and results presented.

\section{RESULTS}

The presented study documented a cross sectional study for the presence of microbial agents in $45.6 \%$ of patients from a total of 147 female patients attending infertility clinic - screened for vaginal infections and the results calculated using excel calculator. Candida species was present in $17 \%$ of patients. $28.6 \%$ of infertility patients had bacteria as etiological agents in vaginitis (Table 1). Gram positive cocci(12.7\%) and Gram negative bacteria (15.7\%) made-up the $28.6 \%$ of isolates. Methicillin Sensitive Staphylococcus aureus(MSSA; $15.8 \%)$, Coagulase Negative Staphylococci(CONS; 42.1\%), Staphylococcus aureus (10.5\%) and Enterococcus species(31.6\%) were the gram positive cocci isolated from high vaginal swab(HVS) samples. The four Gram negative Enterobacteriaceae causative agents of vaginitis in the study were E. coli(43.5\%), Klebsiella species(21.7\%), Acinetobacter species(17.4\%) and Citrobacter species(17.4\%). Maximum infections were observed in 26-30 years age group of patients with age group less than 20 years having the least infection at $2.4 \%$ (Table 2). Six HVS samples from patients showed mixed infections: out of the six mixed infections four were of two different bacteria with three mixed infections involving two Enterobacteriaceae members and one involving E.coli and Enterococcus sp. One of the remaining two mixed infections was of E.coli and Candida with the remaining mixed infection involved three microbes - E.coli, Acinetobacter sp. and Candida. Gentamycin at $91.7 \%$ susceptibility was the antibiotic of choice against all types of Staphylococci with Chloramphenicol being the least effective of

Table 1. Microbial etiology in HVS samples of infertility patients

\begin{tabular}{lcc}
\hline $\begin{array}{l}\text { Result/ Isolated } \\
\text { Microorganism }\end{array}$ & $\begin{array}{c}\text { Frequency } \\
\text { (n) }\end{array}$ & Percentage \\
\hline Negative & 80 & 54.4 \\
Fungi & 25 & 17 \\
Candida spp & 25 & 100 \\
Gram Positive Bacteria & 19 & 12.9 \\
Methicillin Sensitive & 3 & 15.8 \\
Staphylococcus aureus & & \\
Coagulase Negative & 8 & 42.1 \\
Staphylococcus aureus & & \\
Staphylococcus aureus & 2 & 10.5 \\
Enterococcus spp. & 6 & 31.6 \\
Gram Negative Bacteria & 23 & 15.7 \\
E.coli & 10 & 43.5 \\
Klebsiella spp. & 5 & 21.7 \\
Acinetobacter spp. & 4 & 17.4 \\
Citrobacter spp. & 4 & 17.4 \\
Total & 147 & 100 \\
\hline
\end{tabular}

Table 2. Demography of aerobacterial isolates from causing vaginitis in infertility patients

\begin{tabular}{lccccccccc}
\hline $\begin{array}{l}\text { Age group } \\
\text { - years }\end{array}$ & $\begin{array}{c}\mathrm{MSSA} \\
\mathrm{n}(\%)\end{array}$ & $\begin{array}{c}\text { CONS } \\
\mathrm{n}(\%)\end{array}$ & $\begin{array}{c}\mathrm{S} \text {.a } \\
\mathrm{n}(\%)\end{array}$ & $\begin{array}{c}\text { Entero. } \\
\mathrm{spp} .(\%)\end{array}$ & $\begin{array}{c}\text { E.coli } \\
(\%)\end{array}$ & $\begin{array}{c}\text { Kleb. } \\
\text { spp. (\%) }\end{array}$ & $\begin{array}{c}\text { Acineto. } \\
\text { spp (\%) }\end{array}$ & $\begin{array}{c}\text { Citro. } \\
\text { spp. (\%) }\end{array}$ & $\begin{array}{c}\text { Total } \\
(\%)\end{array}$ \\
\hline$>20$ & $0(0)$ & $1(100)$ & $0(0)$ & $0(0)$ & $0(0)$ & $0(0)$ & $0(0)$ & $0(0)$ & $1(2.4)$ \\
$21-25$ & $1(7.7)$ & $4(30.7)$ & $1(7.7)$ & $3(23.1)$ & $1(7.7)$ & $1(7.7)$ & $2(15.4)$ & $0(0)$ & $13(30.9)$ \\
$26-30$ & $2(13.3)$ & $2(13.3)$ & $1(6.7)$ & $3(20)$ & $4(26.7)$ & $1(6.7)$ & $0(0)$ & $2(13.3)$ & $15(35.7)$ \\
$31-35$ & $0(0)$ & $1(33.3)$ & $0(0)$ & $0(0)$ & $2(66.7)$ & $0(0)$ & $0(0)$ & $0(0)$ & $3(7.2)$ \\
$36-40$ & $0(0)$ & $0(0)$ & $0(0)$ & $0(0)$ & $2(50)$ & $0(0)$ & $2(50)$ & $0(0)$ & $4(9.5)$ \\
$<41$ & $0(0)$ & $0(0)$ & $0(0)$ & $0(0)$ & $1(16.7)$ & $3(50)$ & $0(0)$ & $2(33.3)$ & $6(14.3)$ \\
Total & $3(7.1)$ & $8(19)$ & $2(4.8)$ & $6(14.3)$ & $10(23.8)$ & $5(11.9)$ & $4(9.5)$ & $4(9.5)$ & $42(100)$ \\
\hline
\end{tabular}

MSSA - Methicillin Sensitive Staphylococcus aureus; CONS - Coagulase Negative Staphylococcus aureus; S.a-Staphylococcus aureus; Entero. spp.- Enterococcus species; Kleb. spp.- Klebsiella species; Acineto.spp.- Acinetobacter species; Citro. spp.- Citrobacter species; $\mathrm{n}(\%)$ - frequency (percentage) 
Table 3. Antibacterial Susceptibility pattern of Gram Positive cocci associated with vaginitis in infertility patients including CLSI guidelines

\begin{tabular}{|c|c|c|c|c|c|c|c|c|c|c|c|}
\hline Organism & $\mathrm{n}$ & $\begin{array}{l}\text { AMP } \\
n(\%)\end{array}$ & $\begin{array}{c}A K \\
n(\%)\end{array}$ & $\begin{array}{l}\text { COT } \\
\mathrm{n}(\%)\end{array}$ & $\begin{array}{c}C \\
n(\%)\end{array}$ & $\begin{array}{c}\text { CIP } \\
n(\%)\end{array}$ & $\begin{array}{c}E \\
n(\%)\end{array}$ & $\begin{array}{c}\mathrm{G} \\
\mathrm{n}(\%)\end{array}$ & $\begin{array}{l}\mathrm{HLG} \\
\mathrm{n}(\%)\end{array}$ & $\begin{array}{c}\mathrm{LZ} \\
\mathrm{n}(\%)\end{array}$ & $\begin{array}{c}P \\
n(\%)\end{array}$ \\
\hline MSSA & 3 & NT & $3(100)^{*}$ & $2(66.6)$ & $1(33.3)$ & $1(33.3)$ & $3(100)$ & $3(100)$ & NT & $2(100)^{*}$ & NT \\
\hline CONS & 8 & NT & $8(100)^{*}$ & $4(50)$ & $4(50)$ & $5(62.5)$ & $3(37.5)$ & $6(75)$ & NT & $7(100)^{*}$ & NT \\
\hline Staph. aureus & 2 & NT & $2(100)^{*}$ & $2(100)$ & $1(50)$ & $2(100)$ & $2(100)$ & $2(100)$ & NT & NT & NT \\
\hline Enterococcus & 6 & $5(83.3)$ & $3(50)$ & NT & NT & $4(66.6)$ & $2(50)^{*}$ & NT & $5(83.3)$ & $6(100)$ & $4(66.6)$ \\
\hline
\end{tabular}

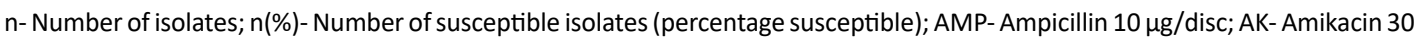

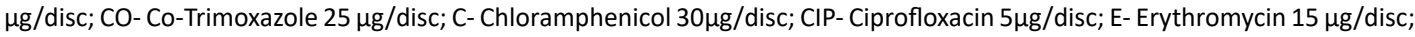

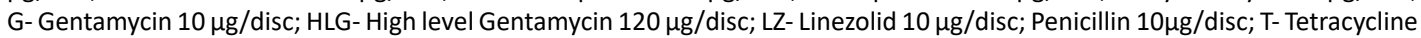
10 mg/disc; NT- Not Tested; MSSA - Methicillin Sensitive Staphylococcus aureus; CONS- Coagulase Negative Staphylococcus aureus; Staph. aureus- Staphylococcus aureus; Enterococcus- Enterococcus species; *- NOT INCLUDED IN CLSI GUIDELINES

Table 4. Antibacterial Susceptibility pattern of Enterobacteriaceae members isolated from infertility patients as per CLSI guidelines

\begin{tabular}{lcccccccc}
\hline Organism & $\mathrm{n}$ & $\begin{array}{c}\text { AMP } \\
\mathrm{n}(\%)\end{array}$ & $\begin{array}{c}\text { AK } \\
\mathrm{n}(\%)\end{array}$ & $\begin{array}{c}\text { AMC } \\
\mathrm{n}(\%)\end{array}$ & $\begin{array}{c}\text { CFS } \\
\mathrm{n}(\%)\end{array}$ & $\begin{array}{c}\text { CAZ } \\
\mathrm{n}(\%)\end{array}$ & $\begin{array}{c}\text { CIP } \\
\mathrm{n}(\%)\end{array}$ & $\begin{array}{c}\mathrm{G} \\
\mathrm{n}(\%)\end{array}$ \\
\hline E.coli & 10 & $4(40)$ & $10(100)$ & $0(0)$ & $8(80)$ & $9(90)$ & $5(50)$ & $8(80)$ \\
Klebsiella species & 5 & $0(0)$ & $5(100)$ & $0(0)$ & $5(100)$ & $3(60)$ & $5(100)$ & $4(100)$ \\
Acinetobacter species & 4 & $2(50)$ & $4(100)$ & $2(100)$ & $3(75)$ & $3(75)$ & $1(25)$ & $3(75)$ \\
Citrobacter species & 4 & $1(25)$ & $2(50)$ & $0(0)$ & $2(50)$ & $1(25)$ & $4(100)$ & $3(75)$ \\
\hline
\end{tabular}

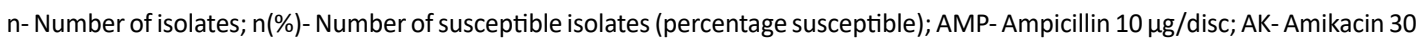

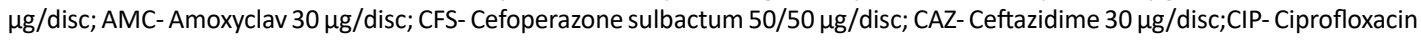
$5 \mu \mathrm{g} / \mathrm{disc} ; \mathrm{G}-$ Gentamycin $10 \mu \mathrm{g} / \mathrm{disc}$.

Table 5. Antibacterial Susceptibility pattern for miscellaneous antibiotics against Enterobacteriaceae members isolated from infertility patients

\begin{tabular}{lcccccccc}
\hline Organism & $\begin{array}{c}\mathrm{C} \\
\mathrm{n}(\%)\end{array}$ & $\begin{array}{c}\text { CTX } \\
\mathrm{n}(\%)\end{array}$ & $\begin{array}{c}\text { CTR } \\
\mathrm{n}(\%)\end{array}$ & $\begin{array}{c}\text { IPM } \\
\mathrm{n}(\%)\end{array}$ & $\begin{array}{c}\text { MRP } \\
\mathrm{n}(\%)\end{array}$ & $\begin{array}{c}\text { NIT } \\
\mathrm{n}(\%)\end{array}$ & $\begin{array}{c}\text { NX } \\
\mathrm{n}(\%)\end{array}$ & $\begin{array}{c}\mathrm{T} \\
\mathrm{n}(\%)\end{array}$ \\
\hline E.coli & $1(100)$ & $4(40)$ & $3(75)$ & $2(100)$ & $2(100)$ & $4(80)$ & $6(66.6)$ & $0(0)$ \\
Klebsiella species & $\mathrm{NT}$ & $3(60)$ & $\mathrm{NT}$ & $\mathrm{NT}$ & $\mathrm{NT}$ & $3(100)$ & $4(100)$ & $0(0)$ \\
Acinetobacter species & $1(100)$ & $0(0)$ & $\mathrm{NT}$ & $1(100)$ & $1(100)$ & $2(50)$ & $3(75)$ & $0(0)$ \\
Citrobacter species & $1(100)$ & $1(25)$ & $1(100)$ & $1(100)$ & $2(100)$ & $3(75)$ & $1(50)$ & $0(0)$ \\
\hline
\end{tabular}

$\mathrm{n}(\%)$ - Number of susceptible isolates (percentage susceptible); C- Chloramphenicol $30 \mu \mathrm{g} / \mathrm{disc}$; CTX- Cefotaxime $30 \mu \mathrm{g} / \mathrm{disc}$;

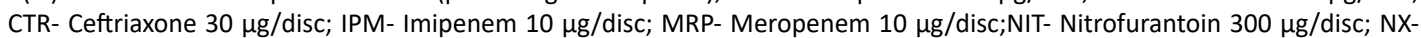
Norfloxacin $10 \mu \mathrm{g} /$ disc; T- Tetracycline $10 \mu \mathrm{g} /$ disc.

all the CLSI guideline antibiotic for Staphylococci. Amikacin and Linezolid among the non-CLSI panel of antibiotic tested in our study was found to be the most effective drug against Staphylococci with all strains tested being $100 \%$ susceptible to these two antibiotics. Enterococci isolated from infertility patients were found to be $100 \%$ susceptible to Linezolid followed by $83.3 \%$ susceptibility to High level gentamycin. Enterococcus sp. were least susceptible to Ciprofloxacin and Penicillin (Table 3).

Antibiotic susceptibility pattern against the four Enterobacteriaceae - E.coli, Klebsiella sp., Acinetobacter sp. Citrobacter sp.; isolated from HVS (Table 4) as per CLSI guidelines indicated Amikacin as the drug of choice in treating such infections as 21 out of 23 strains were determined 
to be susceptible. Ampicillin at $28.8 \%$ susceptibility followed by Amoxyclav at $25 \%$ were determined to be least effective against Enterobacterial pathogens. All the Enterobacteriaceae tested were found to be susceptible to Imipenem, Meropenem and Chloramphenicol. The descending order of effective antibacterials (not included in CLSI guidelines) against enterobacteria as determined in the study was Ceftriaxone, Nitrofurantoin, Nalidixic acid and cefotaxime (Table 5).

\section{DISCUSSION}

Candida sp. as the major isolate in HVS samples is in agreement with previous studies done by Abdul-Aziz et. al. (2019). This high prevalence is the primary reason for the empirical treatment of vaginitis using antifungals. The high prevalence at $62.7 \%$ of bacterial infections in all culture positive among in vaginal swabs of women with infertility mandates the regular isolation of pathogens in women with vaginitis. Prolonged bacterial and fungal infections may cause tubal disorders leading to infertility as documented in studies by Sukatendel et al in 2019. The presence of Chlamydial infections which can be observed in stained tissue sections or serodiagnosed as done in studies done by the authors implies the role of microorganisms in development of infertility in females. The age group 21 to 30 years had the most number of cases with active infectious agents in the vagina implicating the correlation between active sexual behaviour and infection $s^{20}$.

Antibiotic susceptibility of all Gram positive bacterial isolates in the study validates the retainment of Gentamycin with $91.7 \%$ susceptibility (Table 3) by all strains of Staphylococci which was similar to results from studies by Poutrel et. al. (2018) and High-Level Gentamycin at 83.3\% susceptibility by Enterococci ${ }^{23}$. Linezolid (100\%) is the drug of choice to treat Enterococci which is similar to studies by Mendes et al (2018) where they reported more than $95 \%$ susceptibility by Enterococci. Amikacin and Linezolid with 100\% efficacy against Staphylococci in the group of antibacterial not recommended in CLSI for treatment is the novel finding in this study that validates such studies and warrants the setting up of National treatment protocols with probably region-specific treatment regimens and also supported by report of Sharma et al (2018).
Antibiotics like Co-Trimoxazole and Ciprofloxacin that inhibit nucleic acid biosynthesis had an intermediate type of response. The present study documents the higher efficacy in treatment of Gram positive bacteria with protein synthesis inhibiting antibiotics like - Linezolid, Amikacin, Gentamycin or Erythromycin and lower response to cell wall inhibiting antibiotic - Ampicillin which is in agreement with the studies by Bush and Bradford (2019) that documents the production of beta-lactamases.

The present study identified the protein synthesis inhibiting antibiotics - Amikacin and Gentamycin as the being most active against gram negative bacteria isolated from the study population based (Table 4). Third generation cephalosporins - Ceftazidime and Cefoperazone/ Sulbactam were most effective against Gram negative isolates with other cell wall inhibitors having activity in less than $29 \%$ of cases as documented by Krishnasamy et al (2019). Combination of third generation with $\beta$-lactamase inhibitors especially sulbactam increased the efficiency of the drug ${ }^{28}$.

Treatment of Enterobacteriaceae with chloramphenicol is most warranted as all strains tested were found susceptible while all strains are resistant to tetracycline ${ }^{15}$. All strains tested in the study were susceptible to Imipenem and Meropenem the recommended second line antibiotic (Table 5). Treatment with nitrofurantoin may be done on a case by case basis as it was found to be efficient against target bacteria in $76.3 \%$ cases $^{30}$. Statistical analysis for significance gives data that drugs with high susceptibility rates were significant. This analysis does not take into consideration that antibiotic susceptibility varies between strains and susceptibility testing of each isolate is crucial to completely resolving infections.

\section{CONCLUSION}

Candida is the most prevalent organism in vaginitis. Gram positive cocci and gram negative rods were almost equivalent in causing bacterial vaginosis. Overall, Amikacin was found to be the most effective antibiotic. Protein synthesis inhibiting group of antibiotics were found to have greater impact in treatments based on the susceptibility pattern of isolates in the study. Imipenem and Meropenem were found to be 
effective and their use should be restricted to special cases.

\section{ACKNOWLEDGMENTS}

None.

\section{CONFLICT OF INTEREST}

The authors declare that there is no conflict of interest.

\section{AUTHORS' CONTRIBUTION}

All authors have made substantial, direct and intellectual contribution to the work and approved it for publication.

\section{FUNDING}

None.

\section{DATA AVAILABILITY}

All datasets generated or analysed during this study are included in the manuscript.

\section{ETHICS STATEMENT}

The study has been approved by the Institutional Research committee and Institutional Human Ethical committee.

\section{REFERENCES}

1. Kairys N, Garg M., Bacterial Vaginosis. StatPearls Publishing. 2019.

2. Schorge J, Schaffer J, Halvorson L, et al. Cunningham, Williams Gynecology, 2nd Ed. New York : McGraw- Hill Company. 2012:547.

3. Javed A, Parvaiz F, Manzoor S. Bacterial vaginosis: An insight into the prevalence, alternative treatments regimen and it's associated resistance patterns. Microbial Pathogenesis. 2019;127:21-30. doi: 10.1016/j.micpath.2018.11.046

4. Masand D, Patel J, Gupta S. Utility of Microbiological Profile of Symptomatic Vaginal Discharge in Rural Women of Reproductive Age Group. J Clin Diagn Res. 2015;9(3):QC04-QC07. doi: 10.7860/ JCDR/2015/12161.5623

5. Westrom LV. Sexually transmitted diseases and infertility. Sex Transm Dis. 1994;21:532- 537.

6. Han C, Li H, Han L, et al. Aerobic vaginitis in late pregnancy and outcomes of pregnancy. Eur J Clin Microbiol Infect Dis. 2019;38(2):233-239. doi: 10.1007/ s10096-018-3416-2

7. Yano J, Sobel JD, Nyirjesy $P$, et al. Current patient perspectives of vulvovaginal candidiasis: incidence, symptoms, management and post-treatment outcomes. BMC Women's Health. 2019;19(1):48. doi: 10.1186/s12905-019-0748-8

8. Ravel J, Gajer P, Abdo Z, et al. Vaginal microbiome of reproductive-age women. Proc Natl Acad Sci USA. 2011;108(Supplement 1):4680-4687. doi: 10.1073/ pnas.1002611107

9. Winn WC, Stephen A, William J, Gary P. In Koneman's color atlas and textbook of diagnostic microbiology. Lippincott williams \& wilkins. 2006:81-105

10. Katole A, Saoji AV. Prevalence of primary infertility and its associated risk factors in urban population of central India: A community-based cross-sectional study. Indian J Community Med. 2019;44(4):337-341. doi: 10.4103/ ijcm.IJCM_7_19

11. Bitew A, Abebaw $Y$, Bekele D, Mihret A. Prevalence of bacterial vaginosis and associated risk factors among women complaining of genital tract infection. Int J Food Microbiol. 2017: 4919404. doi: 10.1155/2017/4919404

12. Krishnasamy L, Saikumar C, Kumaramanickavel G. Aerobic Bacterial Pathogens Causing Vaginitis in Patients Attending A Tertiary Care Hospital and their Antibiotic Susceptibility Pattern. J Pure Appl Microbiol. 2019;13(2):1169-1174. doi: 10.22207/JPAM.13.2.56

13. Payne MS, Cullinane M, Garland SM, et al. Detection of Candida spp. in the vagina of a cohort of nulliparous pregnant women by culture and molecular methods: Is there an association between maternal vaginal and infant oral colonisation? Aust N Z J Obstet Gynaecol. 2016;56(2):179-184. doi: 10.1111/ajo.12409

14. Coleman JS, Gaydos CA. Molecular diagnosis of bacterial vaginosis: an update. J Clin Microbiol. 2018;56(9):e00342-18. doi: 10.1128/JCM.00342-18

15. Ranjit E, Raghubanshi BR, Maskey S, Parajuli P. Prevalence of bacterial vaginosis and its association with risk factors among nonpregnant women: A hospital based study. Int J Microbiol. 2018;2018:8349601. doi: 10.1155/2018/8349601

16. Mansour A, Mahdinezhad M, Pourdangchi Z. Study of bacteria isolated from urinary tract infections and determination of their susceptibility to antibiotics. Jundishapur J Microbiol. 2009;2(3):118-123

17. Ahmed S, Hossain MA, Shamsuzzaman AKM, et al. Aerobic bacterial pattern in puerperal sepsis. Bangladesh Journal of Medical Microbiology, 2008;2(1):22-27. doi: 10.3329/bjmm.v2i1.21785

18. Suhaib M, Singh S, Verma BS. Isolation and Antimicrobial Susceptibility Pattern of Coagulase Negative Staphylococcus (CONS) Isolated from Various Clinical Samples at a Tertiary Care Hospital, Jaipur, Rajasthan, India. International Journal of Scientific Research. 2020;9(1):67-73.

19. Hudzicki J. Kirby-Bauer disk diffusion susceptibility test protocol. 2009.

20. Abdul-Aziz M, Mahdy MA, Abdul-Ghani R, et al. Bacterial vaginosis, vulvovaginal candidiasis and trichomonal vaginitis among reproductive-aged women seeking primary healthcare in Sana'a city, Yemen. BMC Infectious Diseases. 2019;19(1):879. doi: 10.1186/s12879-019-4549-3

21. Sukatendel K, Mayniar TE, Aboet A, et al. Relationship between Chlamydia Trachomatis Infection with Patency Tubal and Non-Patency Tubal Occurrence in Infertile Women. Open Access Macedonian Journal of Medical Sciences. 2019;7(20):3437-3442. doi: 10.3889/oamjms.2019.440 
22. Poutrel B, Bareille S, Lequeux G, Leboeuf F. Prevalence of mastitis pathogens in France: Antimicrobial susceptibility of Staphylococcus aureus, Streptococcus uberis and Escherichia coli. J Vet Sci Technol. 2018;9:2. doi: 10.4172/2157-7579.1000522

23. Jahansepas A, Aghazadeh M, Rezaee MA, et al. Occurrence of Enterococcus faecalis and Enterococcus faecium in various clinical infections: detection of their drug resistance and virulence determinants. Microbial Drug Resistance. 2018;24(1):76-82. doi: 10.1089/ mdr.2017.0049

24. Mendes RE, Deshpande L, Streit JM, et al. ZAAPS programme results for 2016: an activity and spectrum analysis of linezolid using clinical isolates from medical centres in 42 countries. J Antimicrob Chemother. 2018;73(7):1880-1887. doi: 10.1093/jac/dky099
25. Sharma A, Banerjee M, Mehra M, Khandelwal P, Taneja V. Bacteriology and antibiotic sensitivity of chronic suppurative otitis media in a government hospital. Indian Journal of Otology. 2018;24(4):214.

26. Bush K, Bradford PA. Interplay between $\beta$-lactamases and new $\beta$-lactamase inhibitors. Nat Rev Microbiol. 2019;17(5):295-306. doi: 10.1038/s41579-019-0159-8

27. Ali ET, Abdullah AS, Rana MA. Antibiotic Susceptibility Manner Of The Bacteria Causes Urinary Tract Infections in Basra, South Iraq. J Pure Appl Microbiol. 2020;14(1):541-546. doi: 10.22207/JPAM.14.1.56

28. Devi SS, Sarayu YL, Natarajan V. Antibiotic Susceptibility Pattern of Uropathogens towards Nitrofurontoin and Nalidixic Acid: A Comparitive Study. J Pure Appl Microbiol. 2017;11(3):1567-1572. doi: 10.22207/ JPAM.11.3.42 